\title{
Childhood asthma: exhaled nitric oxide in relation to clinical symptoms
}

\author{
A. Artlich*, T. Busch ${ }^{+}$, K. Lewandowski ${ }^{+}$, S. Jonas*, L. Gortner*, K.J. Falke ${ }^{+}$
}

Childhood asthma: exhaled nitric oxide in relation to clinical symptoms. A. Artlich, T. Busch, K. Lewandowski, S. Jonas, L. Gortner, K.J. Falke. (C)ERS Journals Ltd 1999.

ABSTRACT: Bronchial asthma is associated with increased levels of exhaled nitric oxide which are suppressible by glucocorticosteroid inhalation. Children with bronchial asthma were studied to elucidate the relation between endogenous NO release and recent symptoms of bronchial obstruction.

Twenty-five children with atopic asthma and 11 healthy control subjects were enrolled and exhaled NO was studied using chemiluminescence analysis. The subjects breathed purified air $(<0.5$ parts per billion (ppb) NO) exclusively through their mouths. Orally expired NO was measured during continuous nasal aspiration $(1.3$ $\mathrm{L} \cdot \mathrm{min}^{-1}$ ) to remove nasally produced NO. Nasal NO concentration was determined within the aspirated gas.

Orally expired NO concentration was $2.5 \pm 0.3 \mathrm{ppb}$ (mean \pm SEM) in healthy control subjects, $3.19 \pm 0.88 \mathrm{ppb}(\mathrm{NS})$ in symptom-free children, and $8.28 \pm 0.81 \mathrm{ppb}(\mathrm{p} \leq 0.01)$ in children with bronchial asthma who had had recent symptoms of bronchial obstruction. Similarly, in the subgroup of children treated regularly with inhaled glucocorticosteroids those with recent symptoms had significantly higher orally exhaled NO concentrations than healthy control subjects $(9.5 \pm 1.5 \mathrm{ppb}, \mathrm{p}<0.05)$. The nasal NO concentration was $152.8 \pm 12.7 \mathrm{ppb}$ in healthy control subjects and not significantly different in asthmatic children.

In this group of asthmatic children, recent symptoms of bronchial obstruction were linked to significantly higher concentrations of NO in orally exhaled gas and to increased oral NO excretion rates. If substantiated by further studies, measurement of orally exhaled NO during nasal aspiration may become useful to monitor disease control in asthmatic children.

Eur Respir J 1999; 13: 1396-1401.
*Klinik für Pädiatrie, Medizinische Universität zu Lübeck, Germany. ${ }^{+}$Klinik für Anaesthesiologie und Operative Intensivmedizin, Charité-Campus Virchow-Klinikum, Humboldt Universität Berlin, Germany.

Correspondence: A. Artlich

Karolinska Institute

Dept of Physiology and Pharmacology

Division of Physiology I

S-171 77 Stockholm

Sweden

Fax : 468332047

Keywords: Anti-inflammatory agents asthma

breath tests

child

nitric oxide

steroidal

\section{Received: March 101998}

Accepted after revision January 311999

This study was supported by Deutsche Forschungsgemeinschaft DFG Fal 39/4-1 $\&-2$.
Nitric oxide can be detected in exhaled gas of various mammals including humans [1] and is increased in patients with bronchial asthma [2-8]. In adults, the increase is mainly due to increased production in the lower airways $[9,10]$ although at present it is not clear whether the increased exhaled NO in asthmatics reflects a beneficial response counterbalancing bronchoconstrictor stimuli or contributes to increased tissue damage and perpetuation of immune responses [11, 12]. There is sufficient evidence to conclude that NO synthesis is induced by the underlying chronic inflammatory process in bronchial asthma: in vitro studies have shown the inducibility of NO synthesis by inflammatory cytokines relevant to asthma $[13,14]$. Inducible NO synthase (iNOS) has been detected immunohistochemically in bronchial epithelial cells of asthmatic patients [13] and in alveolar macrophages from areas of chronic inflammation [15]. The inhalation of a pulmonary irritant has been shown to enhance NO production by alveolar macrophages in rats [16]. Furthermore, antigen-induced bronchoconstriction specifically affects exhaled NO levels and is antagonized by endogenous NO in animal studies $[17,18]$. Treatment with glucocorticosteroids reduces the expression of iNOS in macrophages in vitro [19] and leads to a decrease of exhaled NO levels in adults and children with asthma [8, 20, 21].

The major part of exhaled NO normally derives from the nasal region [2, 22-26]. The presence of small amounts of NO in the lower airways has been elegantly proven in tracheotomized and intubated patients [2, 22, 25]. During spontaneous breathing, the detection of NO derived from the lower airways is hampered by variable admixture of nasal NO into the respiratory gas depending, for example, on the position of the soft palate and the presence of a nose clip [26]. In a previous study comparing healthy and asthmatic children [5], a positive correlation between oral and nasal NO concentrations had indicated incomplete separation of the upper and lower airway NO fractions. In the present study, a modified experimental setup with optimized separation of pulmonary and nasal NO [27] was used and endogenous NO release studied in relation to recent clinical symptoms taking into account regular inhalation of glucocorticosteroids. 


\section{Patients and methods}

Thirty-six children (18 female) between the age of 5.5 and 10.3 yrs (median age 8.1 yrs) were entered into the study after consent had been obtained from the local committee on research in human subjects and from the parents. Twenty-five children (median age $8.3 \mathrm{yrs}$ ) suffering from bronchial asthma as defined by the International Consensus Report [28] were recruited from the files of the asthma clinic at Lübeck University Childrens' Hospital $(\mathrm{n}=21)$ or via cooperation with local community paediatricians $(n=4)$. All asthmatic children had had a total serum immunoglobulin $(\mathrm{Ig}) \mathrm{E}>100 \mathrm{kU} \cdot \mathrm{L}^{-1}$ in the past and 13 had a positive family history of atopic disease in first degree relatives. The diagnosis of asthma had been established at least 12 months before the study. The children were suffering from frequent episodic or persistent asthma using current definitions [29]. Eleven children (median age 8 yrs) were healthy control subjects with no history of asthma, atopic dermatitis or atopic rhinitis and without bronchial asthma in first degree relatives. They were not receiving any medication. One child in the asthmatic group and two children in the control group suffered from mild rhinitis on the day of the examination, there was otherwise no history of respiratory tract infection during the preceding 4 weeks.

All asthmatic children and their parents were specifically asked about the occurrence of dry cough at night or on exertion, wheezing, and breathlessness at rest or during exercise. The children were then classified by the presence or absence of any of those symptoms indicative of bronchial obstruction during the 2 weeks preceeding the day of the investigation and subclassified by regular inhalation of glucocorticosteroids (table 1). The latter (budesonide aerosol 200-400 $\mu \mathrm{g} \cdot \mathrm{day}^{-1}$ ) had been applied for at least 4 weeks prior to the study. Other antiasthmatic medication had been administered in standard doses according to clinical severity and are summarized in table 1 .

$\mathrm{NO}$ from the lower respiratory tract was measured in mixed exhaled gas at steady state conditions during tidal breathing. To prevent admixture of nasally produced NO into the orally exhaled gas, nasal gas was removed continuously. This was performed using suction applied via tightly fitted nasal masks (Respironics, Pittsburgh, PA, USA). In the nose, the resulting gas flow was directed from the pharynx through the open velum and through the nasal cavity. Thus, the tidal breathing method recommended by the European Respiratory Society [30] was modified by

Table 1. - Patient groups* and antiasthmatic treatment

\begin{tabular}{|c|c|c|c|c|}
\hline & \multicolumn{2}{|c|}{$\begin{array}{l}\text { Symptom-free } \\
\text { asthma } \\
(\mathrm{n}=12)\end{array}$} & \multicolumn{2}{|c|}{$\begin{array}{l}\text { Symptomatic } \\
\text { asthma } \\
(\mathrm{n}=13)\end{array}$} \\
\hline & Steroids & No steroids & Steroids & No steroids \\
\hline Patients n & 6 & 6 & 5 & 8 \\
\hline $\begin{array}{l}\text { Disodium } \\
\text { chromoglycate } n \\
\text { Short-acting }\end{array}$ & n & 5 & 3 & 6 \\
\hline $\begin{array}{l}\beta_{2} \text {-agonists n } \\
\text { Oral }\end{array}$ & 6 & 5 & 3 & 4 \\
\hline theophylline $\mathrm{n}$ & 2 & 0 & 2 & 0 \\
\hline
\end{tabular}

*:There were also 11 healthy control subjects. the additional maintenance of a continuous nasal suction. A fixed suctional flow rate of $1.3 \mathrm{~L} \cdot \mathrm{min}^{-1}$ was achieved by the use of a pump in combination with a mass flow controller. The experimental setup is illustrated in figure 1. The children breathed orally through a mouthpiece and a water-trap joined to a two-way nonrebreathing flutter valve (opening pressure $<1 \mathrm{cmH}_{2} \mathrm{O}$; Intersurgical, $\mathrm{St}$ Augustin, Germany). This allowed separation of inhaled and exhaled gas; the dead space between mouthpiece and nonrebreathing valves was $44 \mathrm{~mL}$. NO-purified air $(<0.5$ parts per billion (ppb) NO) from a pure air generator (PAG 003; ECO Physics, Duernten, Switzerland) was supplied in excess using a $2.3 \mathrm{~L}$ antistatic rubber reservoir (Dräger, Lübeck, Germany). Inhalation was performed pressure-free via a tube system connected in sidestream.

Subjects exhaled into a $1.7 \mathrm{~m}$ long tube which was distally occluded by a flap valve (Siemens Elema, Solna, Sweden) to prevent retrograde contamination with ambient air. Gas mixing was assured by the total volume of the exhalation tubing, discontinuation of gas flow during the inspiratory phase of the respiratory cycle, and two water traps connected in mainstream. The NO sampling port (Intersurgical) was located at a distance of $1.4 \mathrm{~m}$ from the nonrebreathing valve. A pneumotachograph (Jäger, Würzburg, Germany) allowed continuous monitoring of the respiratory gas flow. Appliances were connected with 22 $\mathrm{mm}$ ID silicone tubes (Dräger). Using $4 \mathrm{~mm}$ ID polyethylene tubes (Intersurgical), mixed exhaled gas was sampled at $1.3 \mathrm{~L} \cdot \mathrm{min}^{-1}$ with a CLD $780 \mathrm{TR}$ chemiluminescence analyser (ECO Physics) calibrated with mass flow controlled dilutions (gas diluter CAL 601; ECO Physics) of certified NO calibration gas (862 ppb; AGA, Bottrop, Germany). The rise time of the NO analyser (time from $0-90 \%$ of full response, P90) was $0.3 \mathrm{~s}$, the detection limit $<0.05 \mathrm{ppb}$. NO concentrations in the ambient air were found to be $<2 \mathrm{ppb}$ during the time of measurements.

NO concentrations were determined after steady state levels had been achieved and were averaged over the first $90 \mathrm{~s}$ of their measurement. Respiratory flow rates and NO concentrations were recorded online with a data aquisition system. After correcting the stored expiratory flow data numerically for the loss owing to nasal suction (21.66 $\left.\mathrm{mL} \cdot \mathrm{s}^{-1}\right)$ average NO excretion rates from the lower airways $\left(\mathrm{nL} \cdot \mathrm{min}^{-1}\right)$ were calculated by multiplication of averaged NO concentrations (ppb) and minute ventilation $\left(\mathrm{L} \cdot \mathrm{min}^{-1}\right)$.

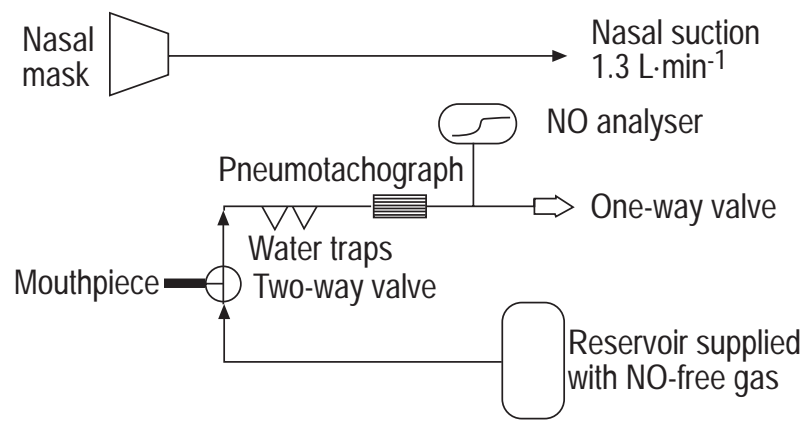

Fig. 1. - Schematic illustration of NO measurement in orally exhaled gas during continued nasal suction. $\rightarrow$ : direction of gas flow. During the measurement of nasal NO the nasal mask was disconnected from the pump and directly connected to the chemiluminescence analyser sampling at the same suction flow $\left(1.3 \mathrm{~L} \cdot \mathrm{min}^{-1}\right)$. 
This is permissible because NO concentrations were determined in mixed exhaled gas.

Nasal NO was sampled using a modification of the setup shown in figure 1 . The sampling port of the chemiluminescence analyser was directly connected to the nasal mask. Nasal NO excretion rates were determined by multiplication of mean nasal NO concentrations (averaged over $90 \mathrm{~s}$ ) with the suctional flow rate of the analyser $\left(1.3 \mathrm{~L} \cdot \mathrm{min}^{-1}\right)$.

The effect of nasal aspiration on measurements in orally exhaled gas was formally studied in four healthy children by comparing results from breathing during nasal suction with those while bearing a nose clamp. Nasal aspiration decreased the NO concentration in orally exhaled gas from $7.8 \pm 0.9 \mathrm{ppb}$ while wearing a nose clamp to $2.7 \pm 0.2 \mathrm{ppb}$.

The repeatability of NO measurements in orally exhaled gas during nasal suction was evaluated as proposed by Azzolin et al. [31] and Bland and AltMAn [32]. For this purpose, two measurements taken on the same day in 10 children were compared. The mean difference of NO measurements in orally exhaled gas (2nd - 1st measurement) was $0.27 \pm 0.11 \mathrm{ppb}$ (mean $\pm \mathrm{SEM}, \mathrm{NS})$. The coefficient of repeatability [32] was $0.69 \mathrm{ppb}$. Greater than $95 \%$ of differences were smaller than this coefficient, revealing a good repeatability of this mode of measurement [32]. Repeatability was thus similar to that obtained by AzzoLIN et al. [31] in healthy children using different methodology.

Lung function was tested plethysmographically (Jäger) using standard normal values for children [33]. As markers of obstructive pulmonary function impairment resistance, forced expiratory volume in one second (FEV1) and maximum expiratory flow at $25 \%$ of vital capacity (MEF25) were retrieved for analysis.

For statistical comparison of the groups, Kruskal-Wallis test with Tukey-Kramer post hoc analysis for multiple comparisons and Mann-Whitney U-test with Bonferroni correction were applied (two-tailed testing). Spearman's rank correlation was applied to test for correlations. Statistical significance was accepted at $p$-values $\leq 0.05$. All results are given in mean \pm SEM.

\section{Results}

Orally exhaled NO concentrations during maintained nasal suction were $2.5 \pm 0.3$ versus $5.8 \pm 0.8 \mathrm{ppb}$ (mean \pm SEM, NS) and the corresponding excretion rates were $18.6 \pm 6.4$ versus $45.6 \pm 6.4 \mathrm{~nL} \cdot \mathrm{min}^{-1}(\mathrm{p}<0.01)$ in the groups of healthy and asthmatic children, respectively. Mean expiratory flow in healthy control subjects was $190.0 \pm 12.5 \mathrm{~mL} \cdot \mathrm{s}^{-1}$ and not significantly different in asthmatic children. Nasal NO concentration was $152.8 \pm 12.7 \mathrm{ppb}$ and the corresponding excretion rate $198.7 \pm 10.1 \mathrm{~nL} \cdot \mathrm{min}^{-1}$ in healthy control subjects, both of which were not significantly different in asthmatic children $(185.2 \pm 13.8 \mathrm{ppb}$ and $240.7 \pm 17.9 \mathrm{~nL}$. $\min ^{-1}$, respectively).

Children with clinical symptoms during the preceding two weeks had significantly higher orally exhaled NO concentrations and excretion rates than symptom-free children with asthma or healthy control subjects (KruskalWallis test, Tukey-Kramer post hoc analysis, $\mathrm{p} \leq 0.01$; table 2). Lung function parameters did not differ significantly between symptom-free and symptomatic children
Table 2. - NO concentrations, excretion rates and pulmonary function parameters in relation to clinical symptoms during the preceeding two weeks

$\begin{array}{ccc}\text { Healthy } & \text { Symptom- } & \text { Symptomatic } \\ \text { control } & \text { free } & \text { asthma } \\ \text { subjects } & \text { asthma } & (\mathrm{n}=13) \\ (\mathrm{n}=11) & (\mathrm{n}=12) & \\ \end{array}$

\begin{tabular}{|c|c|c|c|}
\hline $\begin{array}{l}\text { Orally exhaled NO } \\
\text { concentration ppb }\end{array}$ & $2.5 \pm 0.3$ & $3.2 \pm 0.9$ & $8.3 \pm 0.8$ \\
\hline $\begin{array}{l}\text { Excretion rate in orally } \\
\text { exhaled gas } \mathrm{nL} \cdot \mathrm{min}^{-1}\end{array}$ & $18.6 \pm 3.3$ & $26.6 \pm 3.5$ & $63.1 \pm 9.0$ \\
\hline $\begin{array}{l}\text { Nasal NO } \\
\text { concentration ppb }\end{array}$ & $152.8 \pm 12.7$ & $199.2 \pm 21.1$ & $172.3 \pm 18$ \\
\hline $\begin{array}{l}\text { Nasal excretion rate } \\
\mathrm{nL} \cdot \mathrm{min}^{-1}\end{array}$ & $198.7 \pm 16.5$ & $259.0 \pm 27.4$ & $224.0 \pm 23$ \\
\hline $\begin{array}{l}\text { Minute ventilation } \\
L \cdot \min ^{-1}\end{array}$ & $7.6 \pm 0.5$ & $9.2 \pm 0.7$ & $7.3 \pm 0.5$ \\
\hline Resistance $\%$ pred & $124 \pm 8$ & $168 \pm 21$ & $156 \pm 17$ \\
\hline FEV1 & $106 \pm 2$ & $105 \pm 3$ & $103 \pm 4$ \\
\hline MEF $25 \%$ pred & $95 \pm 4$ & $74 \pm 11$ & $69 \pm 7$ \\
\hline
\end{tabular}

Data are presented as mean \pm SEM. FEV1: forced expiratory volume in one second; MEF25: maximum expiratory flow at $25 \%$ of vital capacity. ${ }^{* *}: \mathrm{p} \leq 0.01$.

with asthma (table 2). There was no correlation between NO levels measured in orally expired gas and in nasally aspirated gas and no correlation of either of these with age or markers of obstructive pulmonary function impairment.

Significantly elevated orally exhaled NO concentrations in recently symptomatic children were found in both steroid-naive $(7.5 \pm 0.9 \mathrm{ppb}, \mathrm{p}<0.01)$ and steroid-treated $(9.5 \pm 1.5 \mathrm{ppb}, \mathrm{p}<0.05)$ subjects in comparison with healthy control subjects. Likewise, NO excretions in those children were significantly higher $\left(52.8 \pm 8.5 \mathrm{~nL} \cdot \mathrm{min}^{-1}, \mathrm{p}<0.01\right.$ and $79.0 \pm 17.9 \mathrm{~nL} \cdot \mathrm{min}^{-1}, \mathrm{p}<0.05$, respectively, fig. 2) than in healthy control subjects. The highest exhaled NO concentrations and excretion rates were found in those children who despite glucocorticosteroid treatment had experienced clinical symptoms during the last two weeks before the study.

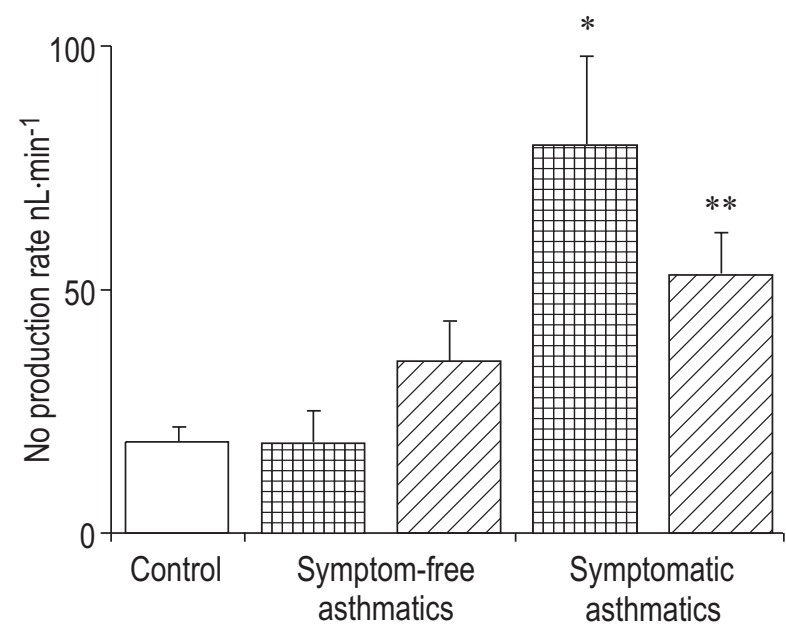

Fig. 2. - NO excretion rates (mean \pm SEM) in orally exhaled gas of asthmatic children and healthy control subjects (control). 㽚: Asthmatic children treated with inhaled glucocorticosteroids; $\mathbb{Z}$ : steroid-naive asthmatic children. $*$ : $\mathrm{p}<0.05 ; * *: \mathrm{p}<0.01$, in comparison with healthy control subjects. 


\section{Discussion}

The present data provide evidence for a significantly higher exhaled NO concentration and excretion rate from the lower airways in symptomatic children with atopic asthma compared with symptom-free children and with healthy control subjects irrespective of glucocorticosteroid treatment. In addition, the data suggest that measurement of NO in orally exhaled gas may be more sensitive to detect deterioration of asthmatic control than standard pulmonary function testing, which revealed no significant differences between the groups.

The application of nasal suction to prevent admixture of nasally produced NO into fractions from the lower airways allowed separate measurements of pulmonary and nasal portions of endogenous NO production. Examining adult lungs in healthy intubated patients, SCHEDIN et al. [25] found $1.3 \pm 0.2 \mathrm{ppb}($ mean \pm SEM) NO in tracheal gas, which is similar to the present finding of $2.5 \pm 0.3 \mathrm{ppb} \mathrm{NO}$ in orally exhaled gas of healthy children. Moreover, they calculated NO release to be $0.2-0.8 \mathrm{nmol} \cdot \mathrm{min}^{-1}[25]$ using the general gas law, the analogous calculation from the present data yields $0.74 \pm 0.13 \mathrm{nmol} \cdot \mathrm{min}^{-1}$. Using bronchoscopic tracheal peak measurements during 15-20 s breath-holds, KHARITONOV et al. [9] and MASSARO et al. [10] found $4 \pm 1$ and $8.2 \pm 1.9 \mathrm{ppb}$ in healthy patients versus $39 \pm 12$ and $32.8 \pm 6.6 \mathrm{ppb}($ mean \pm SEM) in patients with asthma, respectively. These values are higher than the present values because breath-holding will lead to an accumulation of continuously produced NO. In conclusion, NO rates in orally exhaled gas obtained by the present sampling technique can be considered as the upper limit of the NO production in the lower airways. In contrast to the authors' previous work [5], the present data show no correlation between upper and lower airway NO measurements indicating successful removal of nasal $\mathrm{NO}$ from the respiratory gas. The current sampling technique was well tolerated by all participating children.

Recent studies $[34,35]$ have suggested a dependence of lower airway NO excretion on expiratory flow rate. HÖGMAN et al. [35] reported a $25 \%$ increase of NO excretion rate at $300 \mathrm{~mL} \cdot \mathrm{s}^{-1}$ compared to $50 \mathrm{~mL} \cdot \mathrm{s}^{-1}$ using flow restrictors to assure steadiness of the expiratory flow rate. In the present measurements the expiratory flow rate was clearly not constant, but the values for minute ventilation and the corresponding mean expiratory flow rates during $\mathrm{NO}$ measurement as well as the pulmonary function parameters in the different groups of asthmatic children were not statistically different from healthy control subjects. It is thus reasonable to assume that the variation of the expiratory flow rate had comparable effects on the NO excretion rates in all groups of children. Therefore, influences on the significant differences of NO excretion rates between the groups are expected to be minor. This judgement is supported by the fact that Alving et al. [2] described an increased amount of NO in the exhaled gas of asthmatics during tidal breathing even in the presence of confounding nasally produced NO.

The magnitude of NO concentrations in orally exhaled gas of asthmatic children reported in this study defines lower airway NO levels occuring during spontaneous oral breathing more precisely than previous work in adults [2$4,9,10]$ and in children [5-8]. In addition to previous work regarding asthmatic patients in general, the present data demonstrate a difference between symptomatic and symptom-free asthmatic children. As it is shown that continuous nasal aspiration lowers NO concentrations in orally exhaled gas by preventing nasal contamination, it is speculated that exhaled NO measurement during nasal suction may be an alternative to sampling methods which require maintenance of velum closure.

The phenomenon of low orally exhaled NO concentrations and excretion rates in asthmatic subjects treated with glucocorticosteroids has previously been found in adult patients [4]. Moreover, longitudinal studies have shown a decrease of orally exhaled NO after institution of antiinflammatory therapy with inhaled glucocorticosteroids $[8,10,20,21]$, and dose dependency of this suppressive effect [36]. The present data demonstrate that the NO concentrations in orally exhaled gas of successfully treated asthmatic children are within the range of healthy control subjects irrespective of glucocorticosteroid medication. Moreover, recent symptoms of bronchial obstruction are linked to increased NO concentrations in orally exhaled gas even if steroids are part of the medication. Several reasons may explain why some children had very high NO concentrations in orally exhaled gas in spite of glucocorticosteroid treatment. Poor inhalation technique, non-compliance with the inhalation regimen, inadequate glucocorticosteroid dosage or overwhelming inflammatory activity may have played a role.

Use of short acting $\beta$-agonists was more prevalent in the group of asymptomatic patients who had lower NO concentrations compared with recently symptomatic patients. Inhalation of $\beta$-agonists has, on the other hand, been linked to elevations of exhaled NO concentrations in adult asthmatic patients $[37,38]$. Thus, the slightly more frequent use of short-acting $\beta$-agonists in the group of symptom-free children (table 1) is unlikely to explain the lower NO concentrations in orally exhaled gas occuring in this group.

Similar to others $[6,7]$, this study found no significant difference of nasally exhaled NO between healthy children and those with asthma in spite of different experimental setups. This is supported by the recent demonstration of a "fundamental difference" between the regulation of NO production in the lower airways and in the nose, most of which takes place in the paranasal sinuses [7, 23, 24]. In contrast to bronchial epithelium, the mucosa in the paranasal sinuses shows constitutive expression of an inducible-like NO synthase which does not seem to be influenced by treatment with glucocorticosteroids. The reason for elevated nasal NO concentrations in adult asthmatic patients as found by KHARITONOV et al. [9] is therefore unexplained at present.

Recently, several authors have looked at the relationship between exhaled NO levels and asthma severity. TEN HACKEN et al. [39] found no correlation between NO concentration in mixed exhaled air and objective parameters of asthma severity (FEV1, provocative concentration of methacholine and adenosine causing a $20 \%$ fall in FEV1, total eosinophil count, total serum IgE). On the other hand, KHARITONOV and coworkers $[20,36]$ found a decrease of nocturnal symptoms, diurnal peak expiratory flow variability and airway responsiveness to methacholine with decreasing oral exhaled NO concentrations in adults. There was no change of FEV1 in their study, which parallels the present finding of insignificant differences of 
pulmonary function parameters between the study groups. The authors' own previous finding of a weak negative correlation between FEV1 and oral exhaled NO concentration [5] could not be reproduced in the present study. TAYLOR et al. [40], who found no correlation between exhaled NO and airway responsiveness (functionally correlated with FEV1), suggest that the two indicate distinct inflammatory mechanisms. Pulmonary function tests alone may thus not allow definite conclusions about the severity of the asthmatic state.

The present finding of significantly higher exhaled NO values in symptomatic children compared with symptomfree children and healthy control subjects parallels the report of increasing nocturnal cough with increasing exhaled NO concentrations in adults [36]. Therefore, if substantiated in longitudinal studies involving larger numbers of patients, measurement of $\mathrm{NO}$ from the lower airways may offer a promising possibility to monitor effectiveness of antiasthmatic therapy even in young children, at least in addition to pulmonary function tests. However, its usefulness in clinical practice can only be assessed on the basis of further work studying confounding factors influencing its sensitivity and specificity.

\footnotetext{
Acknowledgements. The authors thank all children and their parents for their enthusiastic participation, C. Grywatz for pulmonary function testing, I. Dickau for correspondence with the families, E. de Bary, R. Höhne, S. Mahdi and A. Richter for referring some of the patients for the study, R. Mohnhaupt for providing the software for data retrieval, J.-U. Hagenah, Drägerwerk AG, Lübeck, Germany for stimulating discussions.
}

\section{References}

1. Gustafsson LE, Leone AM, Persson MG, Wiklund NP, Moncada S. Endogenous nitric oxide is present in the exhaled air of rabbits, guinea pigs and humans. Biochem Biophys Res Commun 1991; 181: 852-857.

2. Alving K, Weitzberg E, Lundberg JM. Increased amount of nitric oxide in exhaled air of asthmatics. Eur Respir $J$ 1993; 6: 1368-1370.

3. Persson MG, Zetterström O, Agrenius V, Ihre E, Gustafsson LE. Single-breath nitric oxide measurements in asthmatic patients and smokers. Lancet 1994; 343: 146-147.

4. Kharitonov SA, Yates D, Robbins RA, Logan-Sinclair R, Shinebourne EA, Barnes PJ. Increased nitric oxide in exhaled air of asthmatic patients. Lancet 1994; 343: 133135.

5. Artlich A, Hagenah J-U, Jonas S, Ahrens P, Gortner L. Exhaled nitric oxide in childhood asthma. Eur J Pediatr 1996; 155: 698-701.

6. Dötsch J, Demirakça S, Terbrack HG, Hüls G, Rascher W, Kühl PG. Airway nitric oxide in asthmatic children and patients with cystic fibrosis. Eur Respir J 1996; 9: 25372540 .

7. Lundberg JON, Nordvall SL, Weitzberg E, Kollberg H, Alving K. Exhaled nitric oxide in paediatric asthma and cystic fibrosis. Arch Dis Child 1996; 75: 323-326.

8. Nelson BV, Sears S, Woods J, et al. Expired nitric oxide as a marker for childhood asthma. J Pediatr 1997; 130 : 423-427.
9. Kharitonov SA, Chung KF, Evans D, O'Connor B, Barnes PJ. Increased exhaled nitric oxide in asthma is mainly derived from the lower respiratory tract. Am J Respir Crit Care Med 1996; 153: 1773-1780.

10. Massaro AF, Metha S, Lilly CM, Kobzik L, Reilly JJ, Drazen JM. Elevated nitric oxide concentrations in isolated lower airway gas of asthmatic subjects. Am J Respir Crit Care Med 1996; 153: 1510-1514.

11. Gaston B, Drazen JM, Loscalzo J, Stamler JS. The biology of nitrogen oxides in the airways. Am $J$ Respir Crit Care Med 1994; 149: 538-551.

12. Gustafsson LE. Exhaled nitric oxide production by the lung. In: Zapol WM, Bloch KD, eds. Nitric Oxide and the Lung. Basel, Marcel Dekker 1997; pp. 185-201.

13. Hamid Q, Springall DR, Riveros-Moreno V, et al. Induction of nitric oxide synthase in asthma. Lancet 1993; 342: 1510-1513.

14. Robbins RA, Barnes PJ, Springall DR, et al. Expression of inducible nitric oxide in human lung epithelial cells. Biochem Biophys Res Commun 1994; 203: 209-218.

15. Kobzik L, Bredt DS, Lowenstein CJ, et al.. Nitric oxide synthase in human and rat lung: immunocytochemical and histochemical localization. Am J Respir Cell Mol Biol 1993; 9: 371-377.

16. Pendino KJ, Laskin JD, Shuler RL, Punjabi CJ, Laskin DL. Enhanced production of nitric oxide by rat alveolar macrophages after inhalation of a pulmonary irritant is associated with increased expression of nitric oxide synthase. J Immunol 1993; 151: 7196-7205.

17. Persson MG, Friberg SG, Hedqvist P, Gustafsson LE. Endogenous nitric oxide counteracts antigen-induced bronchoconstriction. Eur J Pharmacol 1993; 249: R7-R8.

18. Persson MG, Gustafsson LE. Allergen-induced airway obstruction in guinea-pigs is associated with changes in nitric oxide levels in exhaled air. Acta Physiol Scand 1993; 149: 461-466.

19. Di Rosa M, Radomski M, Camuccio R, Moncada S. Glucocorticoids inhibit the induction of nitric oxide synthase in macrophages. Biochem Biophys Res Commun 1990; 172: 1246-1252.

20. Kharitonov SA, Yates DH, Barnes M. Inhaled glucocorticoids decrease nitric oxide in exhaled air of asthmatic patients. Am J Respir Crit Care Med 1996; 153: 454-457.

21. Baraldi E, Azzolin NM, Zanconato S, Dario C, Zacchello F. Corticosteroids decrease exhaled nitric oxide in children with acute asthma. J Pediatr 1997; 131: 381-385.

22. Gerlach H, Rossaint R, Pappert D, Knorr M, Falke KJ. Autoinhalation of nitric oxide after endogenous synthesis in nasopharynx. Lancet 1994; 343: 518-519.

23. Lundberg JON, Rinder J, Weitzberg E, Lundberg M. Nasally exhaled nitric oxide in humans originates mainly in the paranasal sinuses. Acta Physiol Scand 1994; 152: 431-432.

24. Lundberg JON, Farkas-Szallasi T, Weitzberg E, et al. High nitric oxide production in human paranasal sinuses. Nat Med 1995; 1: 370-373.

25. Schedin U, Frostell C, Persson MG, Jakobsson J, Andersson G, Gustafsson LE. Contribution from upper and lower airways to exhaled endogenous nitric oxide in humans. Acta Anaesthesiol Scand 1995; 39: 327-332.

26. Kimberly B, Nejadnik B, Giraud GD, Holden WE. Nasal contribution to exhaled nitric oxide at rest and during breathholding in humans. Am J Respir Crit Care Med 1996; 153: 829-836.

27. Busch T, Knorr M, Kuhlen R, Gerlach H, Rossaint R, Falke KJ. Exhaled nitric oxide at rest and during exercise. Am J Respir Crit Care Med 1995; 151: A480. 
28. National Heart Lung and Blood Institute. International consensus report on diagnosis and treatment of asthma. Eur Respir J 1992; 5: 601-641.

29. Warner JO, Naspitz CK, eds. Third international pediatric consensus statement on the management of childhood asthma. Pediatr Pulmonol 1998; 25: 1-17.

30. Kbaritonov S, Alving K, Barnes PJ. ERS task force report: exhaled and nasal nitric oxide measurements. Recommendations. Eur Respir J 1997; 10: 1683-1693.

31. Azzolin N, Baraldi E, Biban P, Vencato F, Zacchello F. Airway nitric oxide (NO) production in healthy children and reproducibility of measurement. Eur Respir J 1995; 8: Suppl. 19, 219S.

32. Bland JM, Altman DG. Measurement error. BMJ 1996; 313: 744.

33. Zapletal A, Paul T, Šamánek M. Die Bedeutung heutiger Methoden der Lungenfunktionsdiagnostik zur Feststellung einer Obstruktion der Atemwege bei Kindern und Jugendlichen. Z Erkrank Atm-Org 1977; 149: 343371.

34. Silkoff PE, McClean PA, Slutsky AS, et al. Marked flowdependence of exhaled nitric oxide using a new technique to exclude nasal nitric oxide. Am J Respir Crit Care Med 1997; 155: 260-267.
35. Högman M, Strömberg S, Schedin U, Frostell C, Hedenstierna G, Gustafsson LE. Nitric oxide f rom the human respiratory tract efficiently quantified by standardized single breath measurements. Acta Physiol Scand 1997; 159: 345-346.

36. Kharitonov SA, Yates DH, Chung KF, Barnes PJ. Changes in the dose of inhaled steroid affect exhaled nitric oxide levels in asthmatic patients. Eur Respir $J$ 1996; 9: 196-201.

37. Yates DH, Kharitonov SA, Barnes PJ. Effect of short- and long-acting inhaled $\beta_{2}$-agonists on exhaled nitric oxide in asthmatic patients. Eur Respir $J$ 1997; 10: 1483-1488.

38. Ho CF, Wang CH, Liu CY, Yu CT, Kuo HP. The effect of bronchodilators on exhaled nitric oxide (NO) in patients with bronchial asthma. Eur Respir J 1997; 10: Suppl. 25, $102 \mathrm{~S}$.

39. Ten Hacken NHT, Meijer RJ, Kerstjens HAM, van der Mark TW, Postma DS. Expired nitric oxide in stable asthmatic patients does not relate to parameters of disease severity. Eur Respir J 1996; 9: Suppl. 23, 416S.

40. Taylor DA, Lim S, Barnes PJ, O'Connor BJ. Exhaled nitric oxide production and increased airway responsiveness in asthma reflect different inflammatory pathways. Eur Respir J 1996; 9: Suppl. 23, 416S-417S. 